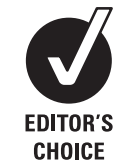

Correspondence to:

Dr N Daniels, Harvard University, Department of Global Health and

Population, Harvard School of

Public Health, Room 1210D,

Bldg 1, 665 Huntington Ave,

Boston, MA 02115, USA;

ndaniels@hsph.harvard.edu

Received 24 July 2008

Accepted 30 July 2008

\title{
Just health: replies and further thoughts
}

N Daniels

\section{ABSTRACT}

This paper responds to discussion and criticism contained in a mini-symposium on Just health: meeting health needs fairly. The replies clarify existing positions and modify or develop others, specifically in response to the following: Thomas Schramme criticises the claim that health is of special importance because of its impact on opportunity, and James Wilson argues that healthcare is not of special importance if social determinants of health have a major causal impact on population health. Annette Rid is concerned that the relevance condition in accountability for reasonableness is unclear and does little work. Harald Schmidt aims to flesh out where an account of responsibility for health should go since one is underdeveloped in Just health. Michael Schefczyk and Susanne Brauer challenge aspects of the prudential lifespan account. Samia Hurst asks what impact a population view should have on clinician obligations.

While my published work is my best effort at a moment to solve certain problems and to explain those solutions, it as also a work in progress, for it is an input into a broader community effort, such as this exchange, to produce knowledge and understanding. I greatly appreciate the hard work put in by the authors of the papers in this symposium. I hope this exchange will clarify what was not clear in Just health: meeting health needs fairly ${ }^{1}$ and uncover views that need more work or significant modification.

My brief remarks that follow take up questions and issues in the same order as I address them in Just health. The book is divided into three parts, successively developing the theory, challenges to it, and applications of it. Part 1, chapter 1 raises three questions of distributive justice: is health of special moral importance? When are health inequalities unjust? And how can we meet health needs fairly when we cannot meet them all? Chapters 2-4 answer these questions in order. Chapter 2 argues that health is of special moral importance because of its significant but limited impact on opportunity, and we have social obligations to protect the range of opportunities open to people. Chapter 3 claims that health inequalities across demographic groups are unjust when they result from an unjust distribution of the socially controllable factors affecting health. I illustrate what I mean by a just distribution of the determinants of health with Rawls' principles of justice as fairness. Conformance with those principles would distribute the key determinants of health (medical, public health and social determinants) so that the socioeconomic status gradient of health is considerably flattened, arguably as much as justice requires it to be. Quite serendipitously, social justice is good for our health. Chapter 4 develops an account of fair deliberative process ("accountability for reasonableness") that is needed to arrive at fair priority setting, since we lack prior agreement on principles fine-grained enough to resolve disagreements about fairness in allocations. Chapter 5 summarises the implications of the theory built around these three answers.

In this symposium, Thomas Schramme challenges the account of the special importance of health developed in chapter 2. Though James Wilson ${ }^{3}$ agrees with my emphasis in chapter 3 on the social determinants of health, he thinks they undermine key conclusions of chapter 2. I take up these issues in the next two sections of this paper. Annette $\mathrm{Rid}^{4}$ gives a sympathetic reconstruction of my discussion of deliberative fair process in chapter 4 and suggests areas for further work. I take up her paper in section 4. One of the points I touch on briefly in chapter 5 is the role of responsibility for health, and this is the focus of Harald Schmidt's paper. ${ }^{5}$ Like Schmidt, I too was not satisfied with the brief discussion or responsibility for health, and I draw on work I have done since Just health to say more in section 5 about the topic.

The second part of Just health, chapters 6-8, addresses three challenges to the theory developed in part one, two of which are touched on in this symposium. The challenge addressed in chapter 6 is the issue of intergenerational justice and how it fits with my account of health and opportunity. My goal is to develop an account of justice between age groups and between adjacent birth cohorts that are affected by institutions distributing such goods as healthcare and income support over the lifespan. In section 6, I address criticisms of my account by Michael Schefczyk ${ }^{6}$ and Susanne Brauer. ${ }^{7}$ Another challenge to my account (see chapter 8 ) is how to reconcile the professional obligations of health providers with constraints imposed by my account of justice for health policy. Samia Hurst ${ }^{8}$ addresses an issue I touch on only briefly in Just health (and spent more time on in Just health care $^{9}$ ), namely how social obligations to distribute health and healthcare fairly translate into the distributive obligations of health professionals. I comment briefly on this issue in section 7 .

The third part of Just health takes up uses of the theory, but these uses are not addressed by the papers in this symposium.

\section{HEALTH AND OPPORTUNITY}

In chapter 2 of Just health I argue that health, construed as normal functioning, ${ }^{i}$ is of special moral importance because we have obligations to protect individual fair shares of the normal opportunity range (NOR), and protecting health contributes to so protecting opportunity. The NOR is the set of reasonable plans of life a 
society's members could pursue (given an otherwise just distribution of resources). Plans are reasonable for an agent if the agent has the relevant talents and skills. (Exercisable opportunities are thus very similar to Sen's capabilities-they are things some can do or be if they choose to (p64-71). ${ }^{12}$ ) An individual fair share of NOR is the set of plans of life a person functioning normally could pursue, given her talents and skills (developed under just conditions). ${ }^{\text {ii }}$ By protecting normal functioning through appropriate health policy (including the just distribution of the social determinants of health), we contribute to protecting individual fair shares of the NOR.

Schramme $e^{2}$ argues that my account is too restrictive because we have two reasons, the reduction of disadvantage and the reduction of suffering, not the one I address (reduction or opportunity), for meeting health needs. ${ }^{\text {iii }}$ Schramme has company here, for others ${ }^{13}{ }^{14}$ have long ago also challenged my focus on opportunity to the exclusion of other reasons for thinking health is important, and I have replied that for purposes of justice, the relation between health and opportunity is central (pp49-50), ${ }^{9}$ though other values, such as beneficence or compassion, may come into play in cases where opportunity cannot be an issue. My concern here is Schramme's argument for his claim. Suppose, he asks in discussing a rather exotic example, that someone has decorative surgery and splits his tongue through informed choice. Schramme asserts that we would not feel obliged to meet his request for speech therapy to compensate for the resulting speech impairment, since he is responsible for causing the disadvantage. If, however, his condition involved suffering, Schramme claims, we would waive our reservations about his responsibility and provide compensation. Shramme infers from this case that suffering, a non-comparative or absolute harm, and not just disadvantage, a comparative harm, is part of the moral significance of disease and disability.

Consider another example. Suppose someone's informed lifestyle choices cause him to have a fatal myocardial infarct and he dies suddenly without suffering (in any ordinary sense). Presumably, the premature death represents a significant loss of opportunity. Would Schramme infer that the lack of suffering means we owe no measures (better health promotion, better rescue efforts) to reduce the risk of such death because the individual is responsible? I think that inference is implausible. But if we owe measures to reduce the risk or to rescue the heart attack victim from death, then we are not discounting

\footnotetext{
${ }^{\mathrm{i}}$ In Just health care (p30), ${ }^{9}$ I grounded my appeal to normal functioning on Boorse's biostatistical account of biological function and of disease; in Just health (p38-40) ${ }^{1}$ I follow Boorse ${ }^{10}$ in saying that normal functioning (and the important concept of pathology) can be grounded in a more eclectic view that admits an etiological account of biological function and some normative component in the characterisation of dysfunction. Specifically, I am neutral between Boorse and Wakefield ${ }^{11}$ and their overlapping but slightly divergent accounts of departures from normal functioning. ii Note that this view is not, as Schramme asserts, the claim that people should have as "many opportunities as possible" given their talents and skills. The claim is they should have the exercisable opportunities they would have were they functioning normally in that context. Schramme also claims that I equivocate between a comparative and non-comparative sense of disadvantage. Sometimes we do need to make comparisons between individuals (eg, in saying someone has a stronger claim on assistance because their needs are greater) and sometimes the judgment is a comparison of the individual with a standard (eg, in saying that someone's diminished health state has reduced their opportunity range from their fair share of the NOR). In any event, on my view justice requires promoting normal functioning even if all individuals equally possess a significant form of pathology — so the view is noncomparative in that sense. Also, even where the view is comparative, its focus is as much on the functioning needed for cooperation and not simply competition.
}

responsibility only where there is suffering, and Schramme's argument for the importance of suffering fails.

Returning to Schramme's own example: despite the individual choice to induce the speech impairment, I think we owe treatment for it (assuming it is part of an array of services that is determined by a fair deliberative process in the system). I return in section 5 to say more about this assertion of social obligation despite individual responsibility. In any case, I do not think our obligations to assist those in significant medical need work the way Schramme suggests.

Schramme claims (in his last section) that I waiver between a Rawlsian and an "egocentric" interest in individuals' fair shares of the NOR. I disagree. My argument for this view is that moral agents, who are capable of forming and revising their conceptions of the good, should have that opportunity space protected so they can exercise that basic moral power. This point has nothing to do with what individuals happen to care about at a given moment. ${ }^{15}$

\section{THE SOCIAL DETERMINANTS OF HEALTH}

I agree with Wilson's claim that, once we realise the importance of the social determinants of health for levels of population health and its distribution, we cannot talk about a theory of justice for health in isolation from an overall theory of justice. Indeed, that is my very claim in Just health. It is the thrust of chapter 3 and the point of the title ("Why justice is good for our health?") of the 1999 paper on which that chapter is based. ${ }^{16}$ It is also the point of my remark in the introduction to Just health that the title of the book is now ironical and not a straightforward pun, as it was in Just health care. I disagree, however, with Wilson's claim that recognising the importance of the social determinants of health shows (a) it is unhelpful or misleading to say that health is of special moral importance, and (b) healthcare can no longer be said to be of special moral importance because other things also are important contributors to health and opportunity.

My argument about the relationship between health and opportunity in chapter 2 is intended to show that protecting health makes a significant contribution to protecting opportunity, and, because we have social obligations to protect opportunity, we have social obligations to protect health. Wilson says this fails to show that "health matters in a fundamental way for justice" because it only says that one effect of protecting health is to protect opportunity. Perhaps we simply disagree about what makes something of special importance ("fundamental" is Wilson's term, not mine). The fact that something (health) makes a significant contribution to something of central importance to concerns about justice, like opportunity, is the content I give to the claim that health is of special moral importance, as recognised in the ways we try to meet health needs more equally than we do preferences for

\footnotetext{
iii Schramme ${ }^{2}$ prefaces this argument with the claim that my notion of normal functioning and its connection to disadvantage is both too strong and too weak. It is too weak: if a normal condition can be disadvantageous (idiopathic shortness), why not treat it? (I reply to this worry at length in chapter 5 and space prevents me from addressing it again here). It is too strong: a pathological condition, such as spotted skin (dyschromic spirochetosis), might be valued by a culture and so not be disadvantageous, yet someone with it might have a claim to be treated. On my view, having a pathological condition provides an eligibility requirement for having claims on medical services, but how important those claims are depends on many factors, including the degree of (negative) impact on opportunity, what can be done for it, what resources there are, and what are the opportunity costs of treating it. In any case Schramme offers no argument, only assertion, for his view that the condition should be treated if someone wants treatment.
} 
many other goods. Within Rawls' theory, I was happy to retain the generality of opportunity as a primary social good without having to add health as another such good.

I emphasise in Just health that my early work on health and opportunity ignored the social determinants of health and made the false assumption that healthcare (broadly construed to include traditional public health measures) was the primary determinant of population health. Indeed, that false assumption misled me into thinking that the three questions of justice I noted earlier all had a common answer: if health was special because it protects opportunity, and if healthcare is the main determinant of health, then inequalities in health are unjust if they result from inequitable access to healthcare. Moreover, we can simply use impact on the opportunity range to rank health needs by importance and allocate healthcare accordingly. But since healthcare (even broadly construed) is only one important determinant of population health and its distribution, answering the first question does not give us answers to the second and third.

Does this mean healthcare (broadly construed) is not of special moral importance? It does not mean that. Even in an ideally just distribution of the social determinants of health (leave healthcare aside) people will encounter disease or injury or disability that undermines their opportunity. Consequently, healthcare remains of special moral importance to protecting opportunity since we cannot prevent all ill health. Must we now also label each of the social determinants as having the same special moral importance because of their impact on health, in effect trivialising the claim about special importance? I agree with Wilson that this attribution of "specialness" seems unnecessary. I would not, however, be opposed to emphasising in public policy the health contribution made by its relevant social determinants. Indeed, that is exactly what we want done in properly designed inter-sectoral policies-we want to consider their health and other impacts. We should know, for example, that the highly inegalitarian tax policy pushed by the George W Bush administration has negative health consequences. Although it is true that we have reasons of justice independent of their impact on health for distributing fairly such social determinants of health as income and education, this does not mean they are not of special moral importance in the sense that they have an impact on health and therefore opportunity that we were some decades ago completely unaware of.

\section{ACCOUNTABILITY FOR REASONABLENESS}

In the Introduction to Just health I remark that I realised in the 1980s and early 1990s that the fair equality of opportunity principle is too general and indeterminate to address a family of what I called "unsolved rationing problems". ${ }^{17}$ For example, when we are thinking of investing in a new service or technology, we may agree that we should give those who are worse off in their health some priority over those who are better off. But we may wonder how much priority we should give them if we can produce much bigger improvement in health for those who are somewhat better off. Similarly, we may agree not to allow many trivial benefits to outweigh significant ones, but we may still disagree about when do modest benefits for larger numbers of people outweigh significant benefits for fewer people. In these and other problems, reasonable people-people seeking reasons that can form the basis for a mutual justification of policy-will disagree about how to make the tradeoffs among the competing values at issue, even if they agree that the overall goal of health policy should be to protect opportunity. We lack prior agreement on more fine-grained principles that tell us how best to protect opportunity in this context. For lack of a consensus on such principles, Jim Sabin and I proposed a form of procedural justice or fair process that we call "accountability for reasonableness". ${ }^{18}$ It requires a search for mutually justifiable reasons, publicity about the grounds for decisions, revisability of decisions in light of new evidence and arguments, and assurance that the process is adhered to.

$\mathrm{Rid}^{4}$ arrives at a characterisation of the process-" constrained pure procedural justice"-which is what we intended to convey. ${ }^{\text {iv }}$ It is "pure procedural justice" because we lack prior consensus on the fine-grained principles needed to resolve disputes about these resource allocation issues, though we may arrive at mutually acceptable justifications through deliberation about specific cases. At the same time the appeal to process is constrained by some prior moral principles. For example, an outcome should not contradict what fair equality of opportunity requires by discriminating against some subgroup on by race or gender. In a context where there is an appeal to human rights protections against discrimination, to be more specific, as in decisions about HIV/AIDs treatment policy or coverage for services within a national insurance plan, as I note in chapter 10, discrimination is excluded. A local decision-making body could not engage in gender or race bias and consider that a fair outcome. Though fair equality or opportunity, including nondiscrimination, constrains acceptable outcomes of fair process, it is too general an idea to settle what counts as an acceptable outcome. That requires agreement, in general by a range of stakeholders, on reasons for thinking an allocation is an acceptable way to meet needs fairly and so protect opportunity for those involved. The point behind insisting on what we call the "relevance" condition is to search for mutually justifiable reasons for thinking that a particular resource allocation is an acceptable way to aim at fair equality of opportunity. The condition takes us beyond mere consistency with fair equality of opportunity since that principle does not determine what to do in the face of disagreements about priorities, aggregation and other problems. ${ }^{v}$

Rid is obviously right that much work needs to be done spelling out what the fair deliberative process should look like at different institutional levels in a health system or in international deliberations about policy. For example, what exactly is the function of relevant stakeholders in the process and how should they be selected? That has to vary with the institutional level, and developing an appropriate and inclusive approach is not a simple matter about which we have a developed body of theory or adequate practice. I carry that discussion as far as I have gone with it in Chapters 9-12 of Just health, but that work on fair process in decision-making about health policy is only just beginning. I welcome efforts to extend it.

\footnotetext{
iv Rid argues that my view of procedural justice is confusingly presented, but I think the discussion of applications of the view in chapters 9-12 should have made the view she arrives at perspicuous.

${ }^{v}$ Since I am not imagining that consensus on relevant reasons will emerge in the fair process, it may be necessary to resolve disputes through a process that involves voting. Whether that involves simple majority votes or super-majorities is a detail of fair process that may depend on the institutional level at which the process is implemented. In Just health and earlier discussions Jim Sabin and I express reservations about relying solely on voting, viewed as a simple aggregation of preferences, and we stress the importance of deliberation as a way of focusing on reasons that even losers in a vote will agree are relevant.
} 


\section{RESPONSIBILITY FOR HEALTH}

Schmidt ${ }^{5}$ is right that Just health is generally silent on the controversies surrounding responsibility for health. In more recent work ${ }^{19}$ I have tried to address that omission, and the approach I take is in general compatible with the approach Schmidt describes in his paper (one stimulus to my work on the topic was a short paper by $\mathrm{Schmidt}^{20}$ addressing several policy efforts to add forms of responsibility for health). Here I state briefly positions that I develop more fully in that recent work and suggest how they fit with some of Schmidt's views.

First, Schmidt and I agree that any acceptable approach to health promotion will have to enlist the population to take some responsibility for healthy lifestyle choices. Of course, we may not know how to do this very effectively, but it is a crucial component of protecting a population against health risks and thus protecting opportunity. I include here a broad range of measures that affect individual lifestyle choices (diet, exercise, safe sex, drug use), care-seeking behaviours (health literacy efforts, immunisation participation), occupational health (compliance with workplace health and safety regulations), and broader public health practices (safe water use, awareness of risks from air and noise pollution, hand washing and other behaviours that prevent infectious disease transmission).

Second, we should reject the view that "you broke it, you own it." However appropriate for china in a gift shop, it fails to address the functions of a system that meets health needsSchmidt and I agree on this point as well. This is not to say we should not recognise the ways in which we value choice. As Scanlon argues, ${ }^{21} 22$ we value choice as a modifier of what we owe people only under certain conditions, and we should distinguish the mere ascription of agency or responsibility from substantive claims about how choice alters what others owe people. This view is a challenge to luck egalitarian accounts (which Scanlon criticises as the "forfeiture view"). I take it to be a feature of luck egalitarian views that what we owe others is not epistemically prior to a determination of what others have brought about for themselves through their "option luck." The view I take in Just health says we can characterise what we owe people by way of meeting health needs without first specifying what people are responsible for having done to themselves and exempting those needs from what we owe them.

In Just health I appeal to but leave undeveloped what I think of as a Rawlsian account of the division between social and individual responsibility for health: society has obligations of justice that specify what social responsibility there is for health, and individuals can pursue their own plans of life within the constraints that justice provides. This Rawlsian ${ }^{23} 24$ approach was expressed in a debate in the early 1980s about "expensive tastes": if someone is unhappy because she likes expensive wines and cannot buy them, then should those with moderate tastes have to compensate them for their deficit in welfare? Rawls says "no" because individuals are responsible for living within the terms set by justice and such social hijacking should not give rise to claims of justice on others. But what about lifestyle choices that are unhealthy and therefore "expensive" for others who may have to share the burden of meeting such health needs? If we explore the (somewhat poor) analogy between some lifestyle choices that affect health and expensive tastes, then we may have to leave the door open to saying that internalising some of the costs of people's choices (through higher deductibles or special insurance policies) is an acceptable component of health policy. This would be a way to hold individuals responsible for living within the requirements of justice that is analogous to not giving people with expensive tastes compensation for not satisfying them outside the health sphere. My constraint on this (partial) internalisation of externalities is that it not be allowed to interfere with people getting needed treatments. Such policies seem to be what Schmidt is open to when he invokes "co-responsibility" as part of the German rationale for policy.

Finally, I note that a luck egalitarian view has some difficulty emphasising health promotion, that is the development of prudent behaviours regarding health. If we are not responsible for compensating people for the disadvantages resulting from informed but imprudent behaviours, then it is not obvious why we owe people health promotion campaigns, except to inform them of what is prudent. We would not seem to owe them incentives to behave prudently. But, a theory that is more directly committed to owing people protection for opportunity, like that in Just health, may have more reason to promote prudence with incentives and not just with information.

\section{INTERGENERATIONAL JUSTICE}

My initial goal in addressing questions of intergenerational justice was to rescue my opportunity-based account from the charge that it was age-biased (aren't the opportunities of older people in their past? If so, shouldn't we give less weight to meeting their health needs?). It became clear to me in the early 1980s, as I struggled with this issue, that there had been no systematic philosophical discussion of justice between birth cohorts or age groups, or about related questions such as rationing by age. The American discussion of the issue was dominated by an analogy with gender and race discrimination and the civil rights legislation addressing them. Yet there is a deep disanalogy with those issues: we all age, but we don't change gender or race. So if institutions that distribute goods over our lifespan treat us differently at different ages, but treat each of us the same way over our whole lives, then objectionable inequalities between persons will not arise as they do with unequal treatment by race and gender. Indeed, if those institutions meet our needs in a prudent manner, we should have no complaint against differential treatment by age.

That thought led me to propose a form of prudential reasoning for thinking about fairness between age groups, assuming we had solved other interpersonal issues of justice. What emerged, however, was a highly modified form of prudential reasoning, one I should probably have put in scare quotes (as I do in what follows) to indicate its departure from the standard, economic model. "Prudent" allocators would not know their age. They must suppose they are designing an institution that provides a good through all stages of their life and they must live through those stages and accept the tradeoffs involved across the lifespan. In my book on justice between age group, ${ }^{25}$ I proposed they be blind to their plans of life and behave more like Rawlsian agents than standard prudent reasoners. Unfortunately, I continued to illustrate such "prudent" reasoning by reference to an individual designing an insurance policy, confusing readers about my departure from standard notions of prudence.

In Just health I began to express some reservations about how well we could use this modified model of prudence to answer questions about how to use resources to make a life go as well as possible. I suggest in chapter 6 (and develop the point further ${ }^{26}$ ) that straightforward maximisation strategies may not settle how we think about making a life go as well as possible. Indeed, reasonable disagreements about how to meet that criterion seem to mean that we must invoke a process like accountability 
for reasonableness to resolve those disputes about prudence. My simplification turns out not to be as simplifying as I thought.

Brauer $^{7}$ senses some of this complexity and my reservations about prudence in her essay, though I draw some different implications than she does. For example, I explicitly say that we cannot resolve disputes about my prudential framework for thinking about age rationing without an appeal to a deliberative fair process, such as accountability for reasonableness. I also believe there is a deep issue reconciling the age group and birth cohort problems, but not the one she points to. The problem is not that the birth cohort problem is "prior" to the age group problem (although I assume a solution to interpersonal justice questions aside from age groups problems), as she claims. Rather, there is a practical problem that declining populations (and working age populations) in developed countries threaten the stability of 20th century "pay as you go" solutions to the age group problem in healthcare and income support schemes, where there is an intergenerational compact that must be sustained.

Schefczyk ${ }^{6}$ is right about my commitment to the view that institutions that distribute resources over the lifespan should view meeting needs as equally valuable at each stage of life. Within the standard view of prudence, this is a version of the claim that we reject pure time preferences. To counter my commitment to that view (argued for in ${ }^{25}$ but not taken up again in detail in Just health), Schefczyk appeals to the claim that we modify our preferences over a life in such a way that we form multiple-selves, not just the one self that might value things in a particular way. I cannot here repeat objections I have made to Parfit's ${ }^{27}$ actual views ( $\mathrm{see}^{28}$ and ${ }^{25}$ reprinted in ${ }^{29}$ ), but I believe Parfit had other forms of weakened psychological connectedness in mind than simply changing preferences over time when he argued for a reductionist view of personal identity and against the irrationality of time preferences. Schefczyk is right, however, in his characterisation of what my argument in ${ }^{25}$ claims (and which I still believe): it is reasonable to assume preferences will change over time, so keeping options open is in general prudent. What Schefczyk and I disagree about is whether the uncertainty Parfit's young Russian faces about whether his future beliefs represent moral decay or moral progress is an adequate basis for a foreclosure of options.

\section{PROFESSIONAL OBLIGATIONS AND JUSTICE}

Hurst $^{8}$ asks how professional obligations should be modified if we take seriously the population view adopted in Just health. Should, for example, clinicians give priority to those worst off in general, or, more precisely, worst off because of the impact on them of the distribution of the social determinants of health, rather than just worst off with regard to health? Should professional obligations on a population view require clinicians to address broader social justice issues and not, as they are currently understood, to meet health needs in proportion to their seriousness regardless of other facts about individuals?

I barely touch in Just health on an argument I made years ago ${ }^{30}$ and drew on in Just health care, namely that our social obligations to meet health needs fairly do not translate directly into individual obligations to do whatever is needed to meet those social obligations. Rather, the social obligations are the basis for the design of institutions and practices within them, and the delegation of tasks to individuals in different roles within those institutions is the way in which individual obligations of justice are determined. Of course, all individuals have duties of justice to promote just institutions: this means professionals and their organisations should not have opposed universal coverage, as they did many times in US history. In response to Hurst, I am inclined to apply that same approach to the relationship between social obligations to meet health needs and professional obligations of clinicians.

Let us imagine that we are in a system that conforms to principles of justice, including justice for health and healthcare. We might suppose (as I do in chapter 3) that socioeconomic status gradients of health are flattened as much as justice requires: social justice is good for our health and its distribution. Should physicians and other health workers then abandon the concern that they meet health needs of individuals in proportion to the claims those needs give rise to? I think not. Individual physicians are not in a position to make judgments about which lives as a whole are worse than others and factor that judgment into their medical recommendations. Rather, institutions are presumably structured to make lives as a whole go as well as justice requires.

So Hurst's concerns focus more on non-ideal contexts, where lack of conformance with general requirements of justice mean we cannot count on institutions producing equity. Here we then face a choice that Hurst notes: should we sustain a wellentrenched view that professionals should address health needs as they encounter them and not as filtered by broader concerns about social justice (which is arguably the view we would want sustained in ideal conditions of justice as well), or should we apply those concerns about social justice in a way that threatens the entrenched view, putting professionals in the role of determining what is fair on non-medical criteria? I think we are more likely to do harm than good if we undermine the entrenched view. This could be taken as a defense of a "separate spheres" view for medical policy even in non-ideal circumstances. This is not to say that in non-ideal circumstances I would be opposed to affirmative action based on class in some contexts, for I accept it with regard to race and gender (in some contexts). The principles that correctly govern our behaviour in ideal versus non-ideal circumstances may well differ. I believe affirmative actions to correct historical racial and gender biases are morally acceptable in certain contexts, even if they differ from the race- and gender-neutral policies that ought to be followed in an ideally just arrangement. This means that we may not afford the luxury of being "colour blind" in non-ideal circumstances even though we should be in ideal contexts. My worry about Hurst's form of affirmative action in the medical context is that such preference would directly counter a presumption that clinicians should not be making social contribution or social worth judgments, and distinguishing them from Hurst's form of affirmative action would be challenging. I do not take my objection to Hurst to be conclusive.

\section{BEYOND THIS EXCHANGE}

As I noted earlier, the third part of Just health takes up uses of the theory. I consider applications of it to health system reform, to the reduction of health disparities, to priority setting in developing countries, and to human rights approaches to health, ending the book with a preliminary discussion of a middle ground in debates about global justice and their implications for international health inequalities. None of the papers in this symposium address these efforts to connect theory and practice, which I view as an important adequacy constraint on moral theory. Theory should guide practice, and if it cannot, that is a problem for the theory. I hope readers of this exchange will be motivated to explore this connection between theory and practice themselves.

Competing interests: None declared. 


\section{REFERENCES}

1. Daniels N. Just health: meeting health needs fairly. New York: Cambridge University Press, 2008.

2. Schramme T. On Norman Daniels' interpretation of the moral significance of healthcare. J Med Ethics 2009:35:17-20.

3. Wilson J. Not so special after all? Daniels and the social determinants of health. $J$ Med Ethics 2009:35:3-6.

4. Rid A. Justice and procedure: how dose "accountability for reasonableness" result in fair limit-setting decisions? J Med Ethics 2009:35:12-16.

5. Schmidt H. Just health responsibility. J Med Ethics 2009:35:21-26.

6. Schefczyk M. The multiple self objection to the prudential lifespan account. J Med Ethics 2009:35:32-35.

7. Brauer S. Age rationing and prudential lifespan account in Norman Daniels' Just health. J Med Ethics 2009:35:27-31.

8. Hurst SA. Just care; should doctors give priority to patients of low socioeconomic status? J Med Ethics 2009:35:7-11.

9. Daniels N. Just health care. Cambridge: Cambridge University Press, 1985.

10. Boorse C. A rebuttal on health. In: Humber JM, Almeder RF, eds. What is disease? Totowa, NJ: Humana Press, 2007:1-134.

11. Wakefield JC. The concept of mental disorder. On the boundary between biological facts and social values. Am Psychol 1992:47:373-88.

12. Daniels N. Capabilities, opportunity, and health. In: Robeyns I, Brighouse H, eds Measuring justice: primary goods and capabilities. New York: Cambridge University Press, forthcoming in 2009.

13. President's Commission for the Study of Ethical Issues in Medicine and Biomedical and Behavioral Research. Securing access to health care. Washington DC: US Government Printing Office, 1983;1.

14. Stern L. Opportunity and health care: criticisms and suggestions. J Med Philos 1983:8:339-62.

15. Buchanan A. Revisability and rational choice. Can J Philos 1975:5:395-408.
16. Daniels N, Kennedy B, Kawachi I. Why justice is good for our health: the social determinants of health inequalities. Daedalus 1999:128:215-51.

17. Daniels N. Rationing fairly: programmatic considerations. Bioethics 1993:7:224-33.

18. Daniels N, Sabin J. Setting Limits fairly: can we learn to share medical resources? New York: Oxford University Press, 2002; Setting limits fairly: learning to share resources for health. $2^{\text {nd }}$ edition. New York: Oxford University Press, 2008.

19. Daniels N. Social and individual responsibility for health. In: Knight C, Stemplowska Z, eds. Distributive justice and responsibility. Oxford; New York: Oxford University Press, 2009; in press.

20. Schmidt H. Health responsibility, the left, and the right. Bioethics Form/Hastings Cent Rep 2007. http://www.thehastingscenter.org/Bioethicsforum/Post.aspx?id $=440$ (accessed 4 Oct 2008).

21. Scanlon TM. The significance of choice. Tanner Lectures on Human Values XIII. University of Utah Press, Salt Lake City, 1988.

22. Scanlon TM. What do we owe to each other? Cambridge, MA: Belknap Harvard, 1998.

23. Rawls J. Social unity and the primary goods. In: Sen AK, Williams B, eds. Utilitarianism and beyond. New York: Cambridge University Press, 1982:159-85.

24. Blake M, Risse M. Two models of equality and responsibility. KSF Faculty Research Working Paper Series. RWP04-032, 2004.

25. Daniels N. Am I my parents' keeper? An essay on justice between the young and the old. New York: Oxford University Press, 1988.

26. Daniels N. Justice between adjacent generations: further thoughts. J Political Theory 2008; in press.

27. Parfit D. Reasons and persons. Oxford: Oxford University Press, 1984

28. Daniels N. Moral theory and the plasticity of person. Monist 1979:62:265-87.

29. Daniels N. Justice and justification: reflective equilibrium in theory and practice. New York: Cambridge Uniersity Press, 1996.

30. Daniels $\mathbf{N}$. What is the obligation of the medical profession in the distribution of health care? Soc Sci Med 1981:15F:129-33. 